\title{
Communications
}

\section{Menadione-Mediated Phosphate Ester Hydrolysis}

\author{
Yunjung Choi, Changwon Oh, and Seung Wook Ham \\ Department of Chemistrv, Chmo-Ang Chiversitw, Seoul 156-756, Korea. "E-mail: swhamiâcau ackr \\ Recerved Mav 15, 2009, Accepted June 15, 2009
}

Key Wonds: Menadione. Phosphatase. Cofactor, Oxygenation, Mechanism

Menadione (2-methỵl-1.4-naphthoquinone. or vitamin $\mathrm{K}_{3}$ ). a synthetic congener of naturally occurring vitamin $\mathrm{K}_{1}$ and $\mathrm{K}_{2}$, has increasingly been of interest given its broad range of antitumor activity in human cells. ' Although oxidative stress was a common mechanism of tumor growth inhibition by menadione. ${ }^{-}$it was reported in 1993 by Juan and Wu that menadione induces alterations in the phosphorylation status of $\mathrm{p} 34^{\mathrm{cdc} ?}$ kinase (cdkl) and the activity of protein ty rosine phosphatases (PTPases) during cell cycle progression. ${ }^{3}$ On the basis of this result, this lab demonstrated that menadione is an inactivator of $\operatorname{cdc} 25$ phosphatase because cdc25 phosphatase dephosphorylates cdk at the Thr-14 and Tyr-15 residues and thus stimulates cdk activity. ${ }^{4}$ Since then, another possible mechanism of menadione cytotoxicity has been ascribed to inactivation of cde 25 phosphatases."

However. some time earlier. Statdman discovered that the phosphatase derived from Clostriditm Sticklandii required the presence of menadione and of added thiol for its activity. The Wu group also pointed out that the p $34^{\text {cac? }}$ activity of menadione-treated cells was increased at early recovery times for unknown reasons. ${ }^{3}$ These observations are interesting as menadione acts as a phosphatase cofactor under certain conditions. differing from the mechanism of action of menadione as a phosphatase inactivator.

Meanwhile. the mechanistic investigations of vitamin $\mathrm{K}_{1}$ have provided evidence for the production of a strong base as the outcome of oxygenation. It has been suggested that the gen-dialkoxide or hydroxide ion in a hydrophobic environment might be possible candidates for the active base. At this
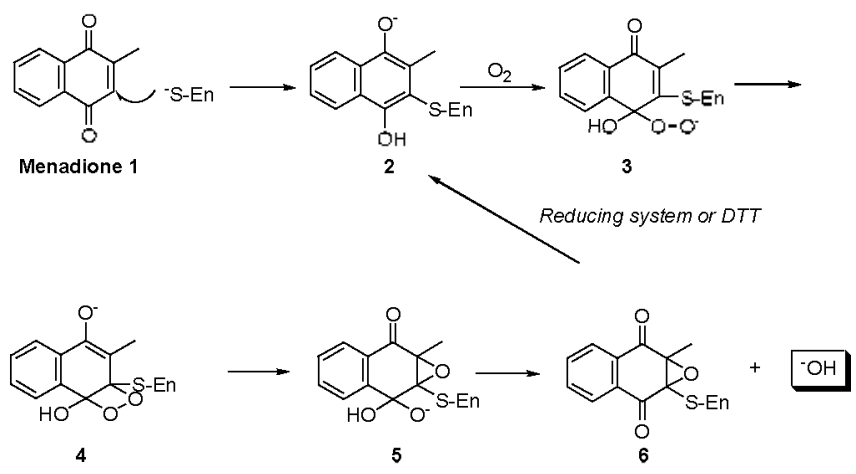

Scheme 1 point. it is the contention of the authors that this capacity to produce the hydroxide ion can be applied to the intriguing observations of phosphatase action. As shown in Scheme 1 . addition of the thiolate group in the enzyme active site would lead directly to hydroquinone anion 2 . If molecular oxygen were a constituent of the active site of the enzyme. trapping with oxygen would then lead to naphthoquinone oxide 6 formation and the production of a hydroxide ion. In the proper hydrophobic setting. the latter can be sufficient to hydrolyze an aromatic phosphate.

To examine the chemical behavior of the hydroquinone anion in the presence of oxygen, first. thiomethyl vitamin $\mathrm{K}$ derivative $7 \mathrm{a}$ was prepared by treatment of menadione with methane thiol. which was then readily converted to the hydroquinone by reduction of the aqueous sodium hydrosulfite. Next, the resulting hydroquinone was treated with $1.0 \mathrm{eq}$. of potassium hydride and 18-crown-6 in THF, and the reaction mixture stirred under an atmosphere of oxygen in the presence of diethyl $p$-tolyl phosphate. We expected that hydrolysis of the phosphate ester would occur by the resulting hydroxide anion during oxygenation. However. treatment with oxygen did not lead to the formation of the expected hydrolysis product. The ${ }^{1} \mathrm{H}-\mathrm{NMR}$ spectrum of the crude product showed small amounts of the corresponding eposy quinine $9 \mathrm{a}^{8}$ no hydroly sis product was detected.

In another model experiment. a tetrahydrofuran solution containing potassium hydroquinone anion $\mathbf{8 b}$. from the reaction of potassium hydride and 2.3-dimethyl naphthohydroquinone, was stirred at room temperature with $18-$ crown-6. Syringe pump

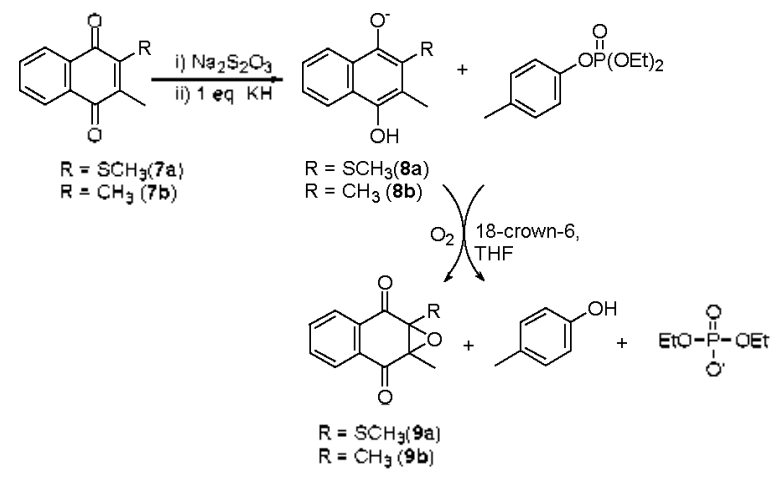

Scheme 2 


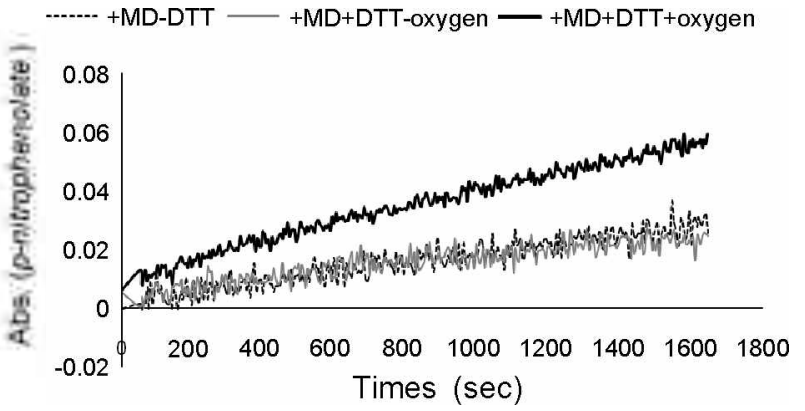

Figure 1. Production of $p$-nitrophenolate by preincubated Cdc25A phosphatase with a high concentration of menadione in the various conditions.

infusion of 2.0 eq of oxygen into the solution yielded the hydrolysis product in $20 \sim 30 \%$ yield. and the naphthoquinone epoxide $9 \mathrm{~b}$ in $40 \sim 50 \%$ isolated yield. The ${ }^{3} \mathrm{H}-\mathrm{NMR}$ spectrum of the crude product, obtained by the ethereal extraction showed eposy quinone $9 b$ with a minor quantity of naphthoquinone $7 \mathrm{~b}$, dietlyl $p$-tolyl phosphate, and two products from phosphatase ester hydrolysis. As expected no hydrolysis product was observed in a control reaction carried out under an oxygenfree atmosphere of nitrogen. showing that the monoanion of 2.3-dimethyl naphtholydroquinone $\mathbf{8 b}$ was not a sufficient mucleophile to hydrolyze the phosphate ester under the reaction conditions. Less than $1 \%$ of tolyl alcohol would readily have been detected by the presence of the three-proton singlet of tolyl alcohol at $2.35 \mathrm{ppm}$ in the $600 \mathrm{MHz}{ }^{1} \mathrm{H}-\mathrm{NMR}$ spectra of the total cnide reaction products. It was important to conduct the control reaction under scrupulously oxygen-free conditions; otherwise. trace amounts of hydrolysis product were observed.

On the basis of these results. the effects of menadione on enzymatic activity were further investigated. Thus. Cdc25A phosphatase was preincubated in the incubation buffer containing $20 \mathrm{mM}$ Tris $(\mathrm{pH} 8.0), 1.0 \mathrm{mM}$ EDTA, and $0.1 \% \beta$ mercaptoethanol, with excess menadione $(100 \mu \mathrm{M})$ that was 20 -fold greater than the $\mathrm{IC}_{50}$ value of menadione against Cdc25A. After a 20 -min preincubation. the enzyme activity was monitored at 410 rum using $40 \mu \mathrm{M} p$-nitrophenyl phosphate as a chromogenic substrate under various conditions. As shown in Fig. 1. there was an increase in the production of $p$-nitrophenolate in the presence of DTT under atmospheric pressure of oxygen, when compared to those in the absence of DTT or without oxygen. These results supported the production of the hydroxide ion by trapping with oxygen as proposed in Scheme 1. It has been established that vitamin $\mathrm{K}$ oxide is easily transformed to vitamin $\mathrm{K}$ by the reductase or in the reducing system. ${ }^{9}$ Therefore the resulting epoxide 6 could also be returned to the starting hydroquinone anion by the reducing agent. DTT. indicating that the irreversibly inactivated enzyme with menadione might dephosphorylate the substrate by the hydroxide ion through the proposed oxygenation cycle.

It is well established that PTPase completes its action in two major steps. ${ }^{10}$ In the first step, the phosphoryl group from the substrate is transferred to the mucleophilic cysteine. forming a phosphoenzyme intermediate. This intermediate is hydro- lyzed, leading to the regeneration of the enzy me and release of an inorganic phosphate in the second step. which has been suggested as a rate-limiting step by the use of kinetic teclniques. Therefore. if molecular oxygen and reducing agents were supplied, the hydroxide ion could be continuously produced as shown in Scheme 1 and readily hydrolyze the phosphate monoester of proteins without the rate-limiting hydrolysis of the phosphoenzyme intermediate. Finally. consistent with observations of phosphatase action by Wu and Statdman the model and enzymatic analyses presented herein. therefore. lead to a new interpretation of the role of menadione as a phosphatase cofactor.

Acknowledgments. This work was supported by the ChungAng University (2008)

\section{References and notes}

1. For reviews, see: (a) Calderon, P. B.: Cadrobbi, J.: Marques, C.; Hong-Ngoc, N.; Tamison, I. M.; Gilloteans, J.: Summers, J. L.; Taper, H. S. Curr. Med. Chem. 2002, 9, 2271. (b) Lamson, D. W.: Plaza, S. M. Altem. Med. Rev 2003, 8, 303 (c) Gerotziafas, G. T.: Papageorgion, C.; Hatmi, M.; Samam, M. M.; Elalamy, I. Pathopinsiol. Haenost. Thromb. 2008, 36, 204.

2. (a) Thor, H.; Smith, M. T.; Hartzell, P,; Bellomo, G.; Tewell, S. A.; Orrenius, S. J. Biol. Chem. 1982, 257, 12419. (b) Ross, D.; Thor, H.; Threadgill, M. D.; Sandy, M. S.; Smith, M. T; Moldeus, P.; Orrenius, S. Arch Biochent. Biophys. 1986, 248, 460. (c) Brown, P. C.; Dulik, D. M.; Tones, T. W. Arch. Biochen. Biophys. 1991, 285, 187. (d) Nutter, L. M.; Ngo, E. O.; Fisher, G. R.; Gutierrez, P. L. J. Biol. Chent 1992, $267,2474$.

3. Juen. C.-C.: Wu, F. Y.-H. Biochem. Biopins. Res. Conm 1993. 190,907

4. (a) Ham. S. W.: Park, H. J.: Lim. D. Y. Bioorg. Chem 1997. 25, 33. (b) Ham, S. W. Jin, S. Song, I. H. Bull Korean Chem. Soc. 2002, 23, 1371. (c) Choi, S.: Han, I.; Park, S.; Ham, S. W. Bull. Korean Chem. Soc. 2008, 29, 1659.

5. (a) Wu, F. Y.: Sun, T. P. Eur. J. Cancer 1999, 35, 1388 (b) Tamura, K.; Solthwick, E. C.: Kens, J.: Rosi, K.: Carr, B. L.: Wilcox C. Lazo, J. S. Concer Res. 2000, 60, 1317. (c) Yoshikawa, K.; Nigorikawa, K.; Tsukamoto, M.; Tamura, N.; Hazeki, K.; Hazeki, O. Biochim. Biopitys. Acta 2007, 1770,687.

6. (a) Stadtman, T. C. J. Biol Chent. $1959,234,636$. (b) Davis, J. N.; Stadtman, T. C. Arch. Biochem. Biophns. 1985, 239, 523.

7. (a) Dowd, P.: Ham, S. W. J.Am Chem. Soc. 1991, 113, 9403. (b) Dowd, P.; Hershline, R.; Ham, S. W.; Naganathan, S. Science $1995,269,1684$. (c) Jung. S.; Ham, S. W. Bull. Korem Chem. Soc. 2007, 28, 1087 .

8. 'HNMR (300 MHz, $C D C l) ; 81.71(\mathrm{~s}, 6 \mathrm{H}), 7.68-7.71(\mathrm{~m}, 2 \mathrm{H})$, $7.92-7.95(\mathrm{~m}, 2 \mathrm{H}) .{ }^{\mathrm{i}} \mathrm{C} \mathrm{NMR}\left(75 \mathrm{MHz}, C D C 1_{3}\right) ; 811.7(\mathrm{q}, J=$ $129 \mathrm{~Hz}), 65.1(\mathrm{~s}), 127.1(\mathrm{~d}, J=164 \mathrm{~Hz}), 132.1(\mathrm{~s}), 134.2(\mathrm{dd}, J=$ $163,8 \mathrm{~Hz}$ ), 193 (s). The IR spectrum (neat) showed at 1693 (s). The mass spectrum showed peaks at me (rel. intensity), 202 $\left(\mathrm{M}^{-}, 23\right), 187(13), 160(47), 131$ (22). Exact mass calculated for $\mathrm{C}_{12} \mathrm{H}_{10} \mathrm{O}_{3}: 202.0630$. found: 202.0630 .

9. (a) Silverman, R. B. J. Am. Chem. Soc: 1981, 103, 5939. (b) Hildebrandt, E. F.; Suttie, T. W. Biochemistry 1982, 21, 2406. (c) Preusch, P. C.; Suttie .T. W. J. Ong. Chem. 1983, 48,3301 . (d) Tie, J. K. Stafford, D. W. I itam. Horm. 2008, 78, 103.

10. (a) Zhang, Z. Y.; Malachowski, W. P.; Van Etten, R. L.; Dixon, I. E. J. Biol. Chem 1994, 269, 8140 (b) McCain, D. F.; Grzyska, P. K.: Wu, L.; Hengge, A. C.; Zhang. Z. Y. Biochentistry 2004, 43, 8256 . 